Article

\title{
Powder Metallurgy Processing and Mechanical Properties of Controlled Ti-24Nb-4Zr-8Sn Heterogeneous Microstructures
}

\author{
Benoît Fer ${ }^{1,2, *}$, David Tingaud ${ }^{1}$, Azziz Hocini ${ }^{1}{ }^{\oplus}$, Yulin Hao ${ }^{3}$, Eric Leroy ${ }^{4}\left({ }^{\circledR}\right.$, Frédéric Prima $^{2}$ \\ and Guy Dirras 1 (D) \\ 1 Université Sorbonne Paris Nord, Laboratoire de Sciences des Procédés et des Matériaux, CNRS, \\ UPR 3407, 93430 Villetaneuse, France; david.tingaud@univ-paris13.fr (D.T.); \\ hocini@univ-paris13.fr (A.H.); dirras@univ-paris13.fr (G.D.) \\ 2 PSL University, Chimie ParisTech, CNRS, Institut de Recherche de Chimie Paris, 75005 Paris, France; \\ frederic.prima@chimieparistech.psl.eu \\ 3 Shi-Changxu Innovation Center for Advanced Materials, Institute of Metal Research, \\ Chinese Academy of Sciences, Shenyang 110016, China; ylhao@imr.ac.cn \\ 4 Université Paris Est Créteil, CNRS, ICMPE, UMR 7182, 2 rue Henri Dunant, 94320 Thiais, France; \\ leroy@icmpe.cnrs.fr \\ * Correspondence: benoit.fer@lspm.cnrs.fr; Tel.: +33-648218555
}

Received: 7 November 2020; Accepted: 1 December 2020; Published: 4 December 2020

\begin{abstract}
This paper gives some insights into the fabrication process of a heterogeneous structured $\beta$-metastable type Ti-24Nb-4Zr-8Sn alloy, and the associated mechanical properties optimization of this biocompatible and low elastic modulus material. The powder metallurgy processing route includes both low energy mechanical ball milling (BM) of spherical and pre-alloyed powder particles and their densification by Spark Plasma Sintering (SPS). It results in a heterogeneous microstructure which is composed of a homogeneous 3D network of $\beta$ coarse grain regions called "core" and $\alpha / \beta$ dual phase ultra-fine grain regions called "shell." However, it is possible to significantly modify the microstructural features of the alloy-including $\alpha$ phase and shell volume fractions-by playing with the main fabrication parameters. A focus on the role of the ball milling time is first presented and discussed. Then, the mechanical behavior via shear tests performed on selected microstructures is described and discussed in relation to the microstructure and the probable underlying deformation mechanism(s).
\end{abstract}

Keywords: heterogeneous microstructure; titanium alloy; powder metallurgy; mechanical properties

\section{Introduction}

$\beta$-metastable titanium alloys are widely used among titanium alloys in aerospace and biomedical application domains. These alloys contain enough $\beta$-stabilizer chemical elements $(\mathrm{Mo}, \mathrm{V}, \mathrm{Nb} \ldots)$ to retain metastable $\beta$ phase at ambient temperature after water quenching from the $\beta$ phase stability field. Because of the metastability of the $\beta$ phase, it is possible to reach various microstructures according to the fabrication process or thermo-mechanical treatments and therefore it gives birth to a wide range of mechanical properties [1].

In this study, we focus on Ti-24Nb-4Zr-8Sn ( $w \mathrm{t} \%$, thereafter called Ti-2448). The weight fraction of niobium in the alloy is high enough to classify it as a $\beta$-metastable type alloy. Zirconium and tin are considered as neutral chemical elements. This alloy is of high interest for biomedical applications because:

- $\quad$ Ti-2448 is only composed of non-cytotoxic chemical elements [2]. 
- Its Young modulus is lower than the one of the other $\beta$ or $\alpha+\beta$ titanium alloys, and significantly lower than the Young's modulus of stainless steel or Cr-Co-based alloys generally used in biomedical applications. Values of Young's modulus around 40 to $50 \mathrm{GPa}$ are quoted for Ti-2448 in multiple studies [3-5].

As a result, it is possible to significantly reduce "stress-shielding" effects which usually occur when the Young's modulus of the implant material is drastically superior to the Young's modulus of human cortical bone. In that case, all mechanical stresses applied on the implanted bone are undertaken by the implant instead of the surrounding bone, which may finally induce bone resorption-according to Wolff's law [6]. This phenomenon has been, for example, studied using a comparison between Ti-2448 and TA6V by Qu et al. on porcine models, resulting in improved results with Ti-2448 implants [7].

Moreover, depending on its initial microstructure, Ti-2448 may benefit from a super-elastic mechanical behavior. Super-elastic alloys are attractive for biomedical application fields, as they allow a better integration of the implant in its new environment. This elastic behavior is due to the stress-induced $\beta$ to $\alpha^{\prime \prime}$ phase transformation, which is reversible and occurs during the first stage of deformation. It allows high values of reversible elastic strain. Stress-induced $\beta$ to $\alpha$ " phase transformation in Ti-2448 has been studied several times [8,9]. Besides, twinning may occur when Ti-2448 is plastically deformed. Nevertheless, the exact nature of twins in the deformed microstructure and the full sequence of deformation in conventional Ti-2448 are not completely understood [10-12].

In order to limit implant replacement surgery, yield strength and fatigue strength are critical cursors to be maximized for orthopedic alloys. Several strategies may be followed to improve yield strength of Ti-2448 [13,14]. Processes based on the precipitation of a second phase of the microstructure (usually $\alpha$ phase in $\beta$-metastable titanium alloys which is related to $\omega$ phase precipitation at low temperature $[15,16])$ are efficient to significantly improve strength of the $\beta$-metastable alloys [17]. Other hardening strategies are based on the chemical design of the alloy. Using Bo-Md diagrams, it is possible to control the deformation mode of the alloys [18], and to induce transformation-induced plasticity (TRIP) or twinning-induced plasticity (TWIP) effects $[19,20]$. Grain refinement could also be used as a hardening strategy, by the development of ultrafine-grained (UFG) structures, which can be obtained via severe plastic deformation or powder metallurgy processing routes. However, these structures generally suffer from a significant lack of ductility [21]. To face the problems of ductility losses, heterogeneous grain structures have been elaborated on several studies, and they have proved to be an efficient way to maximize the strength-ductility synergy of different materials [22-24].

One particular heterogeneous microstructure is the so-called harmonic structure, which is composed of an interconnected and homogeneous 3D network of fine grains regions called "shell" and coarse grain regions called "core." The fabrication process of harmonic microstructure is based on powder metallurgy, including low energy mechanical ball milling (BM) and sintering (spark plasma, hot isostatic pressing) of pre-alloyed and spherical shaped powder particles [25-28]. Although a range of titanium powders have been consolidated using SPS/FAST [29-31], a very few attempts have been published in literature to fabricate Ti-2448 via powder metallurgy route. On the one hand, sintering of Ti-2448 has been made from elemental powder particles by Li et al. [32] but the sintered material could not achieve full density. Metal Injection Molding of pre-alloyed Ti-2448 particles was achieved by Kafkas et al. [33]. The results are promising despite the precipitation of $\mathrm{Ti}_{x} \mathrm{C}$ carbides along the grain boundaries. Additive manufacturing (including both Electron Beam Melting and Selective Laser Melting) was also successfully applied on Ti-2448 [34-36]. On the other hand, the elaboration process of harmonic microstructures has been successfully performed on several materials, including steel [27,37], $\mathrm{CP} \alpha$ titanium and $\alpha+\beta$ TA6V alloy [25] and $\beta$-stable Ti-25Nb-25Zr alloy [38]. In many cases, it results in an improvement of both yield strength and ultimate tensile strength almost without a ductility loss, even when deformation modes switch from mechanical twinning to dislocation glide [39].

In this work, the effect of heterogeneous grain structures and precipitation hardened structures are combined by processing a specific dual-phase harmonic microstructure based on the Ti-2448 alloy. Heterogeneous structured Ti-2448 samples with various microstructural features (including $\alpha$ 
precipitates volume fraction, core and shell fraction, grain sizes) have been fabricated via the control of mechanical BM parameters. The link between the resulting microstructures and the mechanical behavior of the alloy is further discussed.

\section{Materials and Methods}

Ti-2448 spherical shaped powder particles which have been argon atomized at the Institute of Metal Research (IMR) from the Chinese Academy of Sciences have been used as raw materials for this study. A sieving stage has been performed after gas atomization to sort powder particles according to their size. For this work, powder particles whose diameter is in the range 100-160 $\mu \mathrm{m}$ have been chosen, as they allow a good balance between core and shell in the final heterogeneous microstructures. Mechanical BM has been performed by the use of a Pulverisette 7 premium line planetary ball mill (FRITSCH, Idar-Oberstein, Germany), using both jar and $10 \mathrm{~mm}$ diameter balls made of steel. No significant iron or carbon contamination was detected after BM in a steel environment. Rotational speed of the mill was fixed at $200 \mathrm{rpm}$, using a ball-to-powder ratio (BPR, weight ratio) of 2:1. BM time is the varying parameter of the study $(0 \mathrm{~h}, 12 \mathrm{~h}, 25 \mathrm{~h}, 50 \mathrm{~h}$, and $100 \mathrm{~h})$. Names of the as-processed samples are the following: IP (for initial powder) when the starting powder was directly sintered, BM $12 \mathrm{~h}$ for a BM time of $12 \mathrm{~h}$, BM $25 \mathrm{~h}$ for a BM time of $25 \mathrm{~h}$, etc. For the consolidation step, Spark Plasma Sintering (SPS) was performed using Dr. Sinter 515 S Syntex (Fuji Electronic Industrial co., Tsurugashima, Japan) setup belonging to the "Plateforme de Frittage Île-de-France" (Thiais, France). Cylindrical samples whose diameter is $20 \mathrm{~mm}$ and height are $2 \mathrm{~mm}$ were fabricated under argon atmosphere, and sintering parameters were fixed and chosen in order to ensure complete densification of the powder. Therefore, a sintering temperature of $800{ }^{\circ} \mathrm{C}$ and a compressive pressure of $100 \mathrm{MPa}$ were applied for $30 \mathrm{~min}$. Heating rate is $50{ }^{\circ} \mathrm{C} / \mathrm{min}$. For illustration purposes, a typical sintering cycle is displayed on Figure 3.

The microstructural characterization of the samples was performed using a scanning electron microscope SUPRA 40VP (ZEISS, Iena, Germany), equipped with a field-emission gun and an Electron BackScatter Diffraction (EBSD) acquisition system. Chemical analysis was performed using Wavelength Dispersion Spectroscopy (WDS) or Energy Dispersive Spectroscopy (EDS) techniques on an electron probe microanalyser SX100 (CAMECA, Gennevilliers, France). The WDS analyses were recorded at a voltage of $15 \mathrm{kV}$ and an electric current of $40 \mathrm{nA}$. For EBSD acquisition $400 \mu \mathrm{m}^{2}$ or $800 \mu \mathrm{m}^{2}$ zones have been analyzed most of the time, with a respective step size of $0.25 \mu \mathrm{m}$ or $0.5 \mu \mathrm{m}$. Both $\beta$ and $\alpha$ phase data have been used to index patterns using OimDC NORDIF software (version VS2005, EDAX, Weiterstadt, Germany). OIM Analysis software (version 5.3, EDAX, Weiterstadt, Germany) was used to analyze EBSD data. X-ray diffraction (XRD) measurements were acquired using a diffractometer Equinox 1000 (INEL, Artenay, France) with a copper $(\lambda=0.1540 \mathrm{~nm})$ or cobalt $(\lambda=0.1789 \mathrm{~nm})$ monochromatic radiation. Data from the cobalt radiation diffractometer are converted to data which would have been collected using a copper experimental setup in order to ensure coherency of the results. Phase identification was based on Match software database. Density measurements were performed using Archimedes' principle in o-xylene liquid.

Mechanical properties were investigated via simple shear tests, using a home-made shear setup mounted on an MTS M20 testing machine (MTS Systems Corporation, Eden Prairie, MN, USA). The load capacity of the shearing device is $100 \mathrm{kN}$. Rectangular samples whose thickness is in the range 1.6-1.8 $\mathrm{mm}$ and width in the range 16-17 $\mathrm{mm}$ were cut along the radial direction of the cylindrical pads which are obtained after SPS. They are settled between two jaws, including one of them which is fixed and the other one which is moving vertically to shear the sample. The sheared volume is similar for every mechanical test. The deformation is followed directly on the sample, by using a video extensometer and computing the variation of the shear angle between a black line drawn on the surface of the sample and its initial horizontal position. These tests were performed at room temperature, at a shear strain rate of $10^{-3} \mathrm{~s}^{-1}$. 


\section{Results and Discussion}

\subsection{Powder Metallurgy Processing Route}

The fabrication process is based on powder metallurgy. The powder particles which have been used for this study have been obtained via argon atomization of a cylindrical pre-alloyed Ti-2448 alloy ingot. The initial morphology of the powder particles is shown in Figure 1a. They are mostly of spherical shape and their diameters are in the range 100-160 $\mu \mathrm{m}$. The largest particles are surrounded by satellite particles which have not been shown to play any role during the process. Moreover, each powder particle is composed of single polycrystalline $\beta$ phase, as it can be seen in the Inverse Pole Figure (IPF) map of a selected representative powder particle (Figure 1b) or on the X-ray diffraction pattern (XRD) of the initial powder (IP on Figure 2e). The average grain size in a representative initial powder particle is $15 \mu \mathrm{m}$ (Figure $1 \mathrm{~b}$ ).

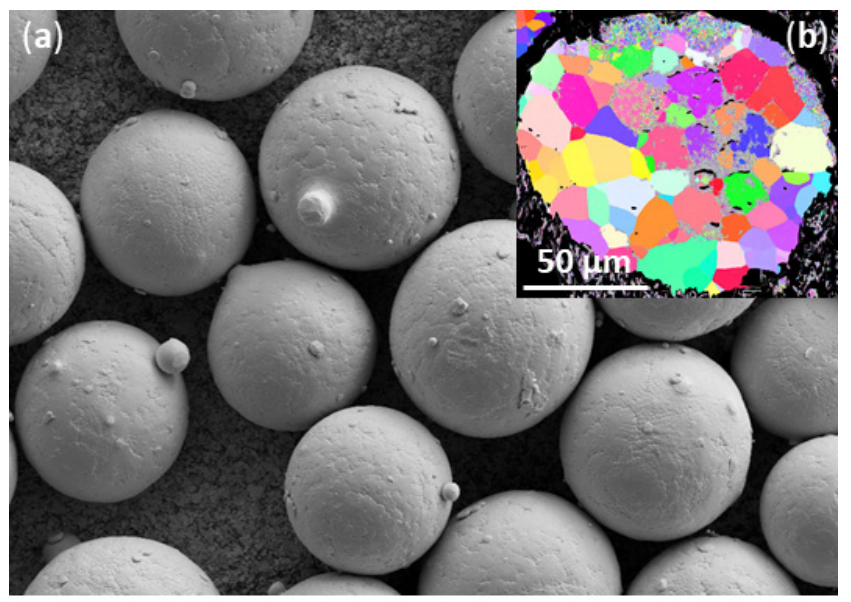

\section{$100 \mu \mathrm{m}$}

Figure 1. Characterization of initial powder particles (a) Scanning Electron Microscope (SEM) secondary electron image of the powder, (b) Inverse Pole Figure (IPF) image of a selected powder particle highlighting its microstructure.

The first stage of the fabrication process of this dual phase heterogeneously structured Ti-2448 is the mechanical planetary BM of the powder. Low energy parameters are selected for BM, as the objective of this stage is to induce superficial plastic deformation on the powder particles without affecting the core.

Figure 2 displays the morphology of the powder particles after BM for different BM times. The effect of BM on the morphology of powder particles is clear from a BM time of $12 \mathrm{~h}$ after which powder particles have lost their spherical shape. For a longer BM time ( $25 \mathrm{~h}$ and $50 \mathrm{~h}$ ), some particles are severely affected by BM and are indicated by white arrows on Figure $2 b-d$. Furthermore, after BM for $100 \mathrm{~h}$, fragmentation of some particles occurs: the fragments are indicated by red arrows on Figure 2d. XRD patterns are also plotted in Figure 2e for powders after BM. The results confirm the high plastic deformation which is induced on powder particles during BM stage. Indeed, a significant broadening of the $\beta$ phase peaks - especially the main $\beta\{110\}$ peak_takes place when increasing the BM time. Inset in Figure 2e plots the evolution of the full width at half maximum (FWHM) of the main $\{110\}$ peak. A global increase in the FWHM occurs, but it is worth noting that the increase is not linear. A clear broadening of the peak is noted after a BM of $12 \mathrm{~h}$. The evolution is then smoother between $12 \mathrm{~h}$ and $50 \mathrm{~h}$, before increasing again for a BM time of $100 \mathrm{~h}$. It means that plastic deformation of the powder is very high at that last BM level. Moreover, we can clearly observe the appearance of an additional peak in the XRD pattern of the $50 \mathrm{~h}-\mathrm{BM}$ and $100 \mathrm{~h}-\mathrm{BM}$ powders, which is indicated by a black star on Figure $2 e$ and could be indexed as hexagonal or orthorhombic titanium 
phase. However, because mechanical BM is not supposed to induce the precipitation of hexagonal $\alpha$ phase in the powder, it is possible that reversible stress-induced martensitic transformation $\beta$ to $\alpha$ " occurs during BM. Incomplete reversion of this transformation (because $\alpha$ " precipitates may be trapped by dislocations or other deformation traces) might explain the presence of this extra peak [12]. Nevertheless, the thermo-elastic behavior of the orthorhombic martensitic phase allows the complete reversion of it when heated at a moderate temperature, as it is the case during the first stage of sintering. As a result, this extra phase might not have a significant impact on the processing route.

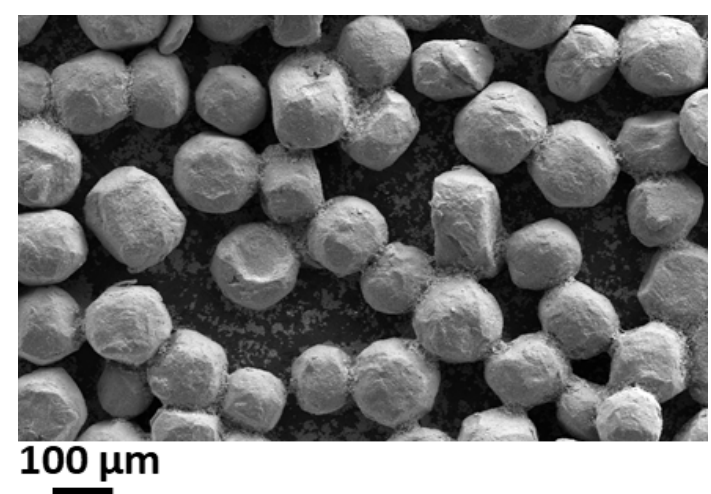

(a)

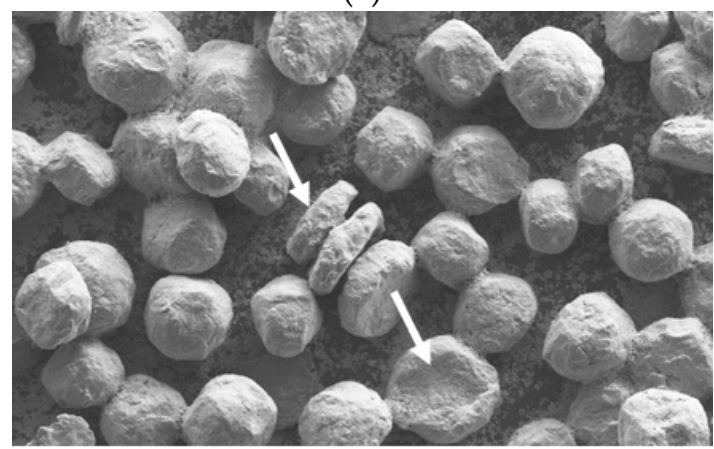

$100 \mu \mathrm{m}$

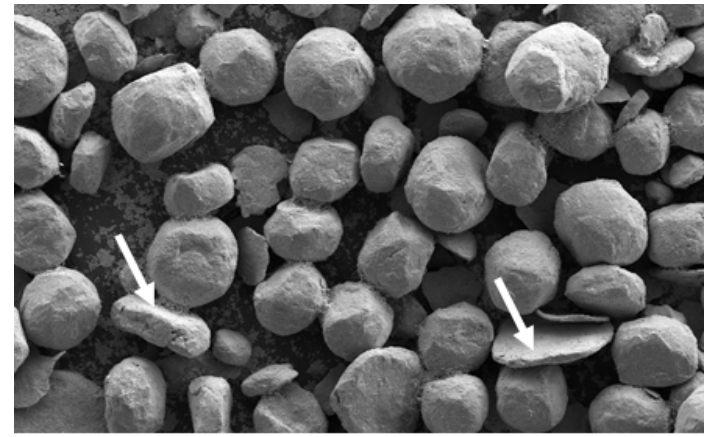

$100 \mu \mathrm{m}$

(b)

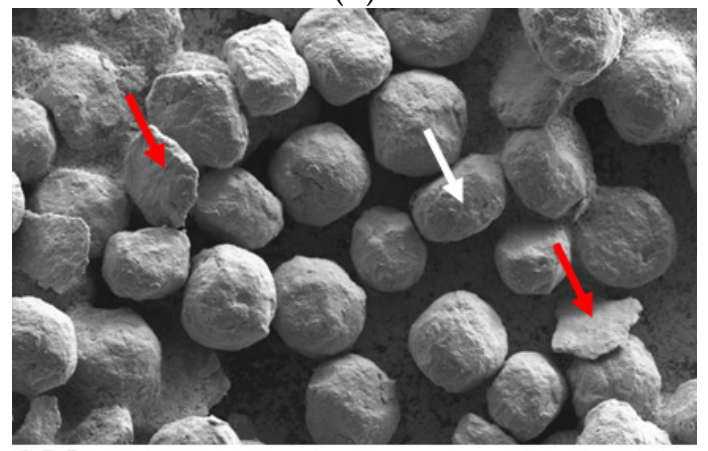

$100 \mu \mathrm{m}$

(d)

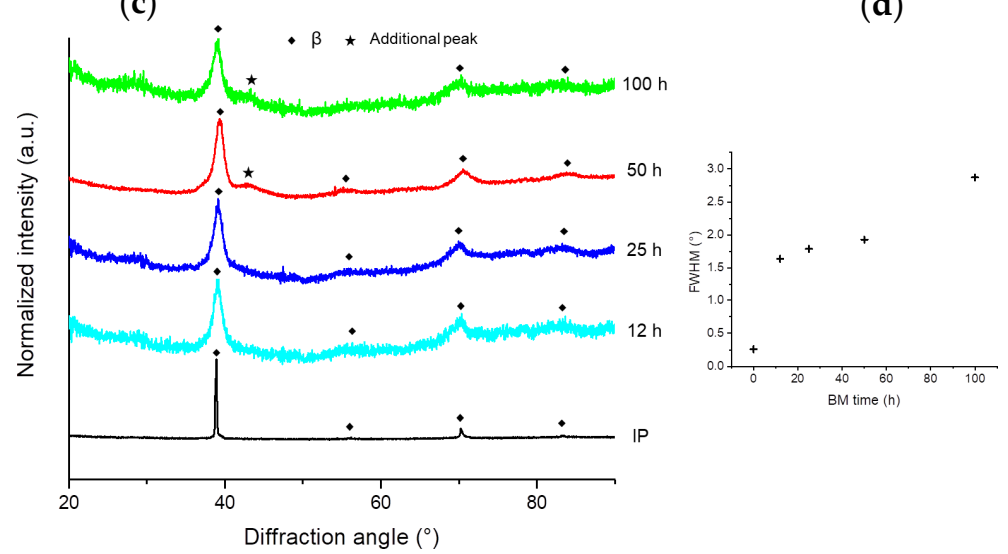

(e)

Figure 2. Characterization of ball-milled powders (a) SEM secondary electrons image after $12 \mathrm{~h}$ ball milling (BM) (b) after $25 \mathrm{~h} \mathrm{BM} \mathrm{(c)} \mathrm{after} 50 \mathrm{~h} \mathrm{BM}$ and (d) after $100 \mathrm{~h} \mathrm{BM}$. (e) X-ray diffraction (XRD) results of Ti-2448 powders after BM, including diffractograms for each BM time and the corresponding evolution of the full width at half maximum (FWHM) of the main $\{110\} \beta$ phase peak.

All samples have been sintered using the same SPS cycle, so that only BM time has been modified between samples during the whole fabrication process. Figure 3 is a comparative plot of the SPS 
responses of $\mathrm{IP}, \mathrm{BM} 12 \mathrm{~h}$, and $\mathrm{BM} 50 \mathrm{~h}$. It shows the evolution against time of the temperature, pressure, and derivative of the displacement of the piston during sintering of the three samples. This last parameter is useful to follow the densification of the samples during SPS, which takes place in two steps. The first one is associated with cold compaction of the powders, at ambient temperature once the pressure is applied. The second one occurs when the temperature reaches the beginning of sintering temperature. That time is indicated with arrows for each sample on Figure 3 and is associated with the effective sintering of the material. As we can see, BM affects the sintering reactivity of the powders, as the sintering temperatures are not the same for each sample. The longer the BM time is, the lower the sintering temperatures are. It means that the sintering reactivity of the powder particles has been increased by mechanical BM via storing mechanical energy in the material and increasing the density of structural defects in it. Therefore, diffusion phenomena are favored during sintering which consequently occurs at a slightly lower temperature.

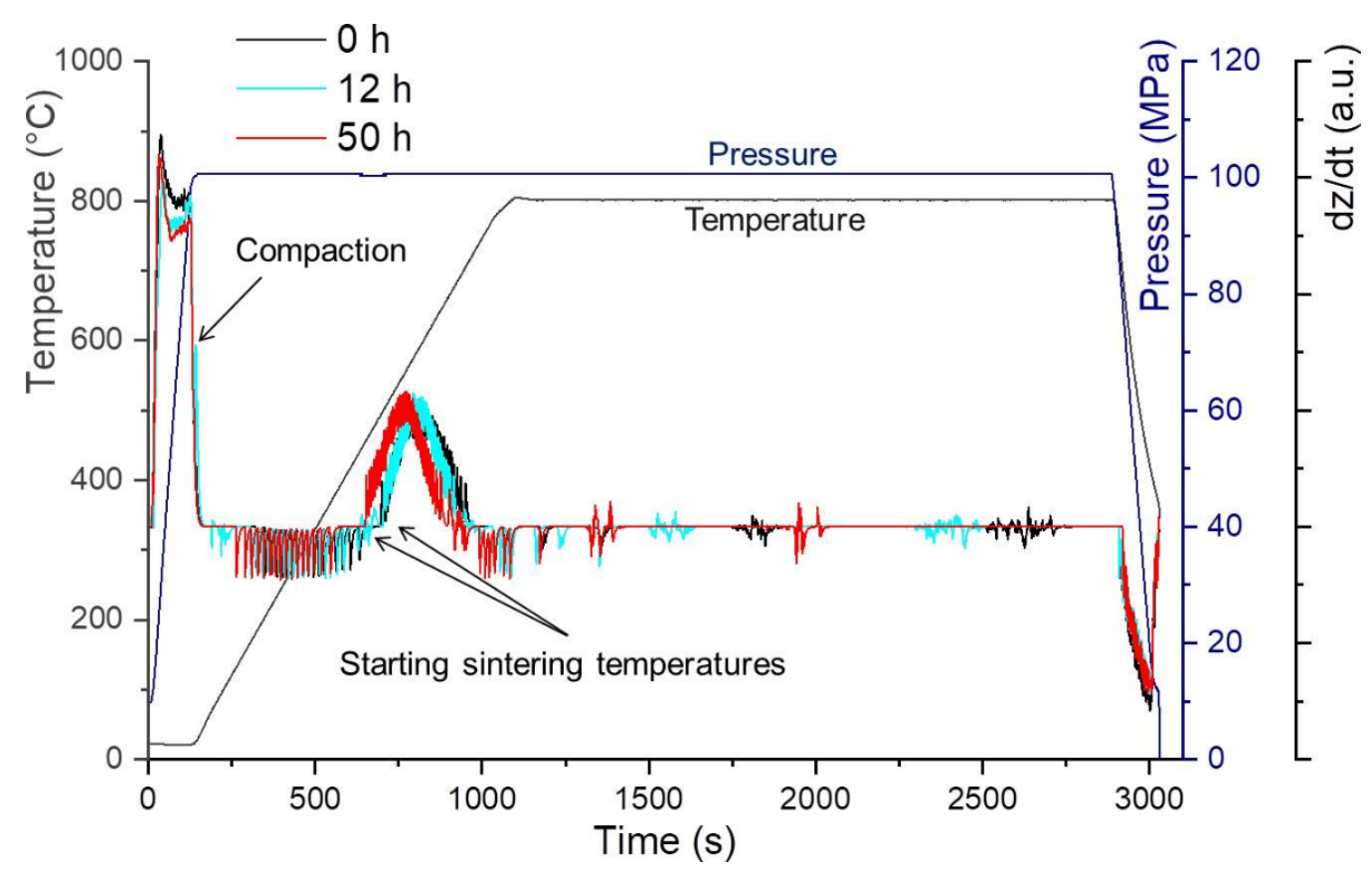

Figure 3. Spark Plasma Sintering (SPS) cycle showing the evolution against time of temperature, pressure and the derivative of the displacement of the piston of IP, BM $12 \mathrm{~h}$, and BM $50 \mathrm{~h}$.

The SPS stage has two main goals: the first one is to obtain dense materials and the second one is to allow recrystallization of the heavily deformed surface of powders, whose volume is directly connected to the BM time (Figure 2e). This recrystallization is therefore the key phenomenon to induce the formation of the fine grain region called "shell."

\subsection{Microstructural Features of the As-Sintered Samples}

The fabrication process - which includes both BM and SPS—-has resulted in dense samples with a relative density of $100 \%$. For each processed sample, the density is measured via Archimede's method and compared with the theoretical density of the material. The theoretical density of single $\beta$-phase Ti-2448 has been calculated using XRD data of an as-sintered single-phase IP sample. The cell parameter of the single phase $\beta$-BCC structure, which has been computed via Rietveld refinement of the XRD results, is $3.300 \AA$ and the corresponding calculated theoretical density of a full $\beta$ Ti-2448 structure is $5.44 \mathrm{~g} / \mathrm{cm}^{3}$. This value is confirmed in literature by Li et al., who have found a close value of $5.46 \mathrm{~g} / \mathrm{cm}^{3}$ [32]. 
Illustrations of a typical heterogeneous microstructure, which is obtained at the end of the processing route, are given in Figure 4. As it is illustrated, the as-sintered microstructures are heterogeneous and bimodal:

- $\quad$ Firstly, they contain two populations of $\beta$ phase grains homogeneously dispersed in the whole volume of the sample. The first one consists in fine grains-with an average grain size of about 4 to $5 \mu \mathrm{m}$ depending on the sample-and is located at every zone where plastic deformation occurs during BM. It constitutes the "shell" of the harmonic structure. The other one is made of coarse grains - the average grain size in the core against BM time is plotted for every sample on Figure $7 \mathrm{~b}$-and is formed in the core of the powder particles, where no plastic deformation was produced by the BM stage. It constitutes the "core" of the harmonic structure. The presence of fine $\beta$ grains is clearly observed on the close-up views of Figure 4 . The shell region may also be separated into the outer-consisted of micron-wide $\beta$ grains-and inner shell consisted of grains about hundreds of nanometers wide.

- Secondly, they are bimodal from a chemical point of view, as they contain $\alpha$ phase precipitates near the shell. In most samples, the core is exclusively consisted of $\beta$ phase and no $\alpha$ phase has been detected (except for BM 100 h). As we can see in Figure $4 b$, the average grain size of $\alpha$ precipitates is $1 \mu \mathrm{m}$ and they are located at the $\beta$ grain boundaries in the shell vicinity. They benefit from the excess of energy due to grain boundaries to precipitate during sintering.

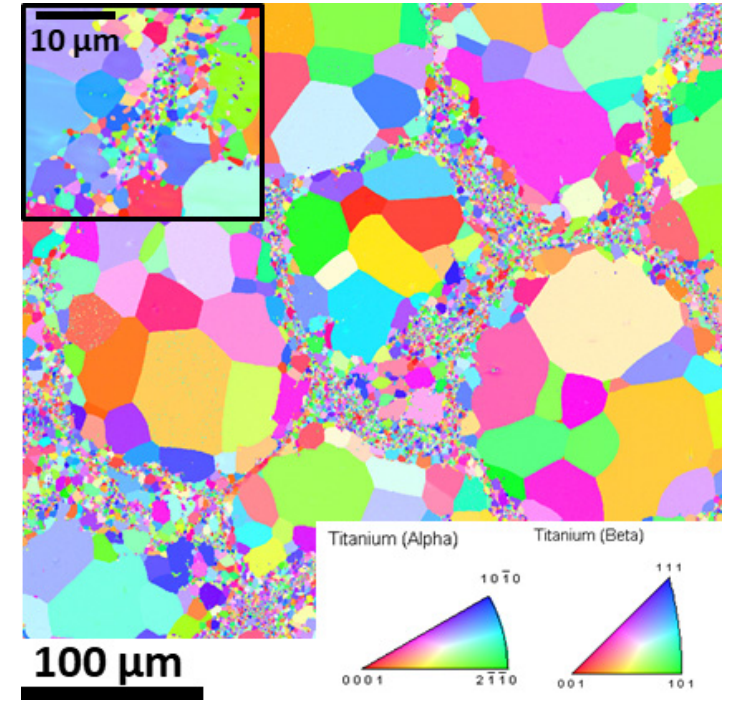

(a)

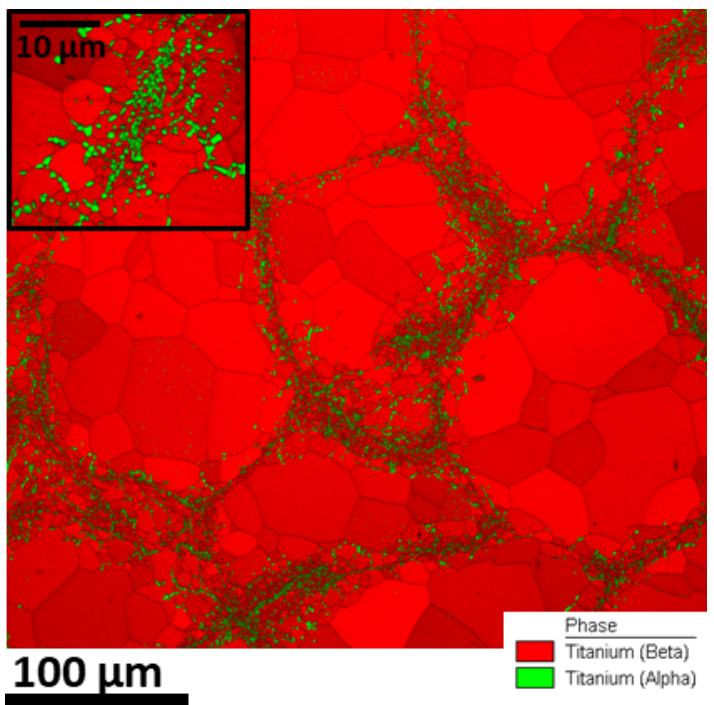

(b)

Figure 4. The microstructural characterization of BM $25 \mathrm{~h}$. (a) $400 \mu \mathrm{m}^{2}$ IPF image and a close-up view of the shell region framed in black (b) corresponding phase image and a close-up view of the shell framed in black.

However, chemical composition of the alloy at this stage of the fabrication process could also be the cause of $\alpha$ phase precipitation. Figure 5 shows WDS maps of chemical elements repartition in the harmonic microstructure of BM $50 \mathrm{~h}$ sample. The shell which is composed of both $\alpha$ and $\beta$ phases is enriched in titanium (Figure 5b) and depleted in niobium (Figure $5 c$ ), which is a $\beta$-stabilizer chemical element. Besides, Figure 5d clearly shows a local enrichment in oxygen in the shell vicinity, which probably enhances local $\alpha$ phase precipitation. Oxygen is indeed a strong $\alpha$-stabilizer chemical element $[40,41]$. The oxygen contamination probably occurs during the mechanical BM stage, as the longer BM is processed, the higher the oxygen content in the alloy is. 


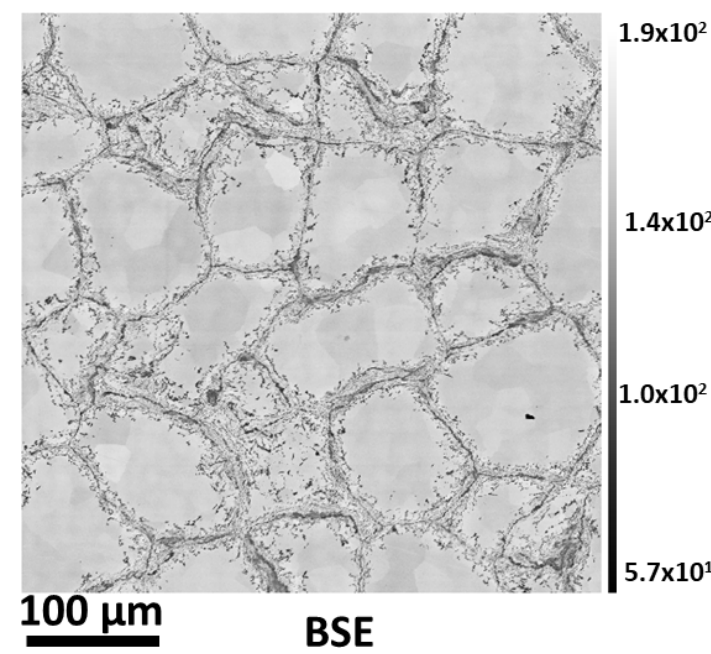

(a)

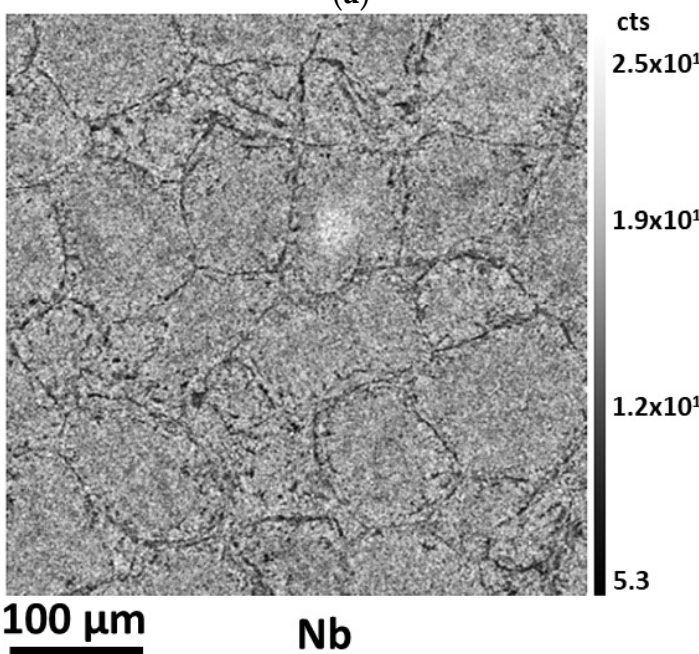

(c)

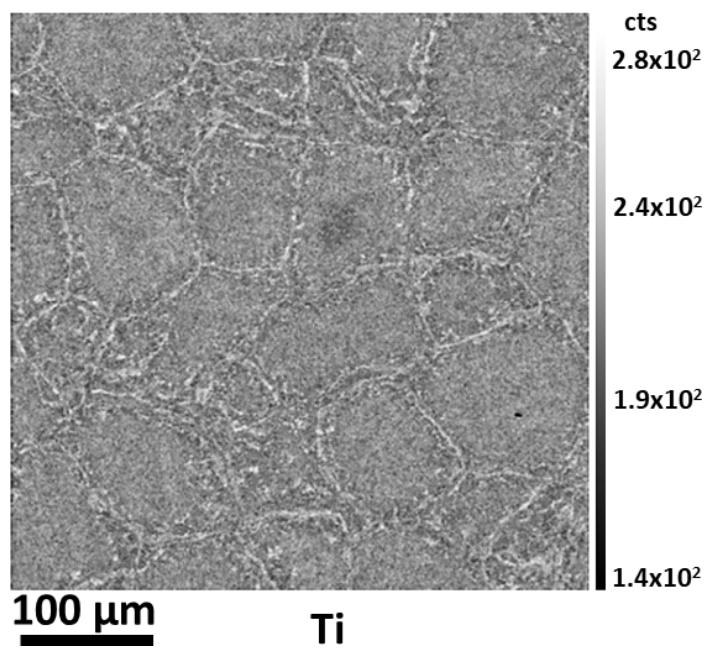

(b)

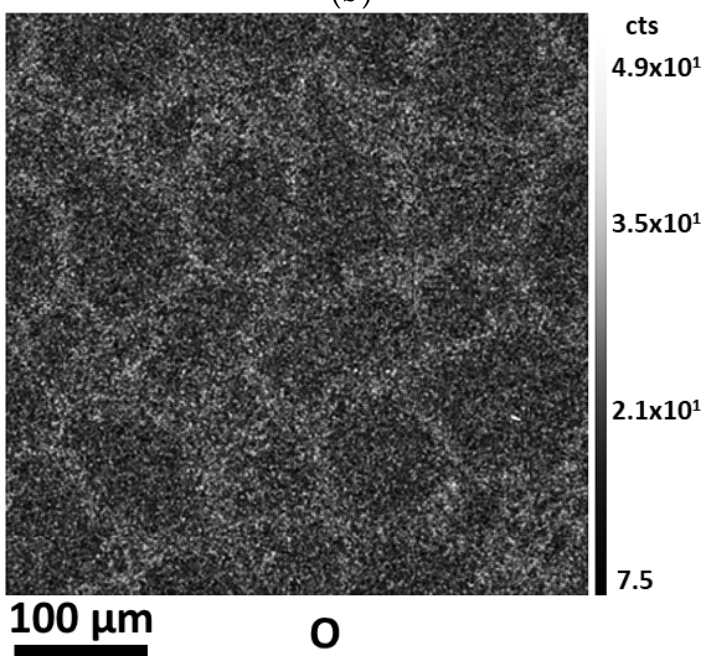

(d)

Figure 5. Chemical mapping of a BM $50 \mathrm{~h}$ sample. (a) Back-scattered electron image and corresponding (b) Ti repartition map, (c) $\mathrm{Nb}$ repartition map, and (d) O repartition map.

This investigation shows that it is possible to modify the microstructural features of the harmonic microstructures by playing with the processing parameters. The focus was made on the influence of $\mathrm{BM}$ time on the final microstructures. BM is indeed of primary importance in the fabrication process: it must be low energetic to avoid fracture of powder particles and high enough to induce local plastic deformation on the surface of the powder particles. Figure 6 shows IPF and grain size maps of 5 different samples fabricated using various BM times of $0 \mathrm{~h}, 12 \mathrm{~h}, 25 \mathrm{~h}, 50 \mathrm{~h}$, and $100 \mathrm{~h}$. Grains are considered to belong to the shell when their diameter is less than $10 \mu \mathrm{m}$. The other grains are considered to belong to the core of the microstructure. All the parameters which have been calculated, including shell surface fraction, $\alpha$ phase surface fraction and grain sizes in the core and in the shell are evaluated thanks to EBSD data. Note that an average grain size in the shell has been calculated for both $\beta$ and $\alpha$ phases. The main microstructural features of the as-sintered samples are summarized in Table 1. 


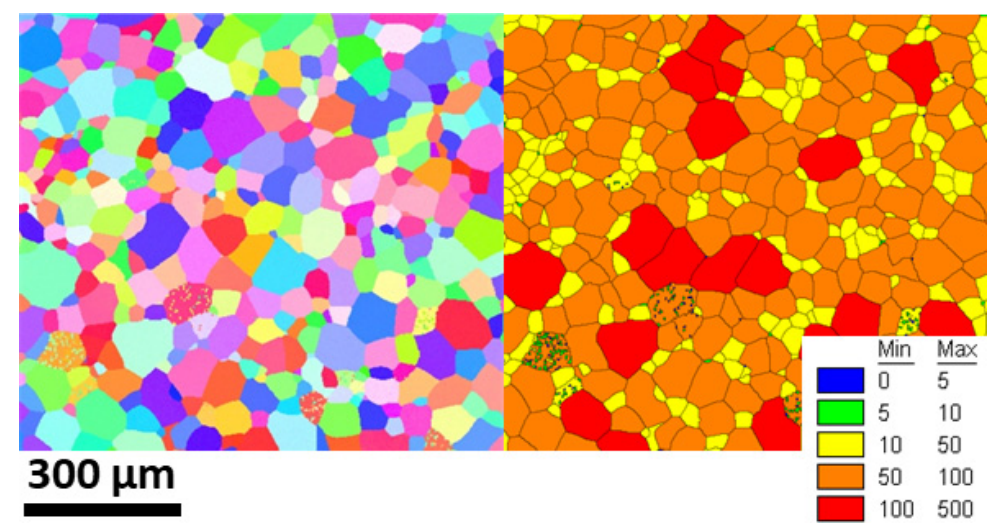

(a)

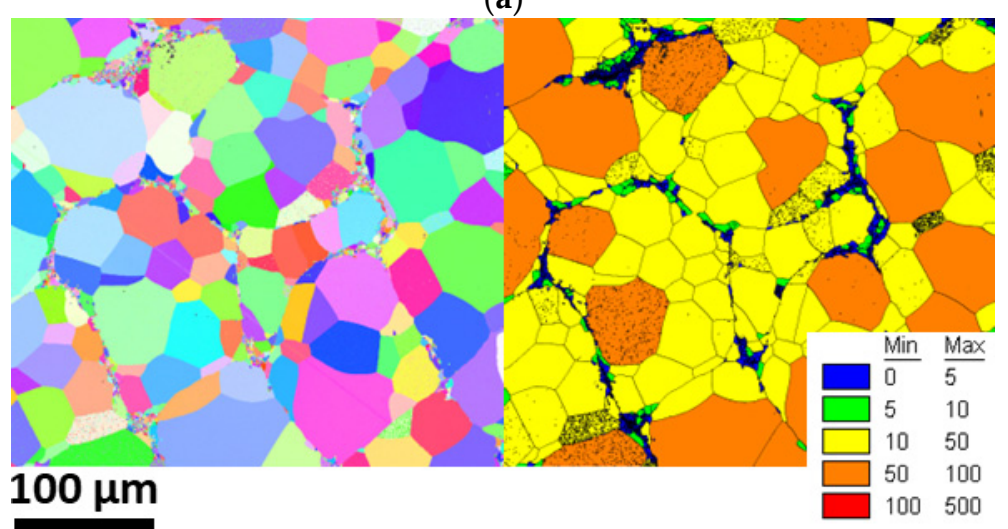

(b)

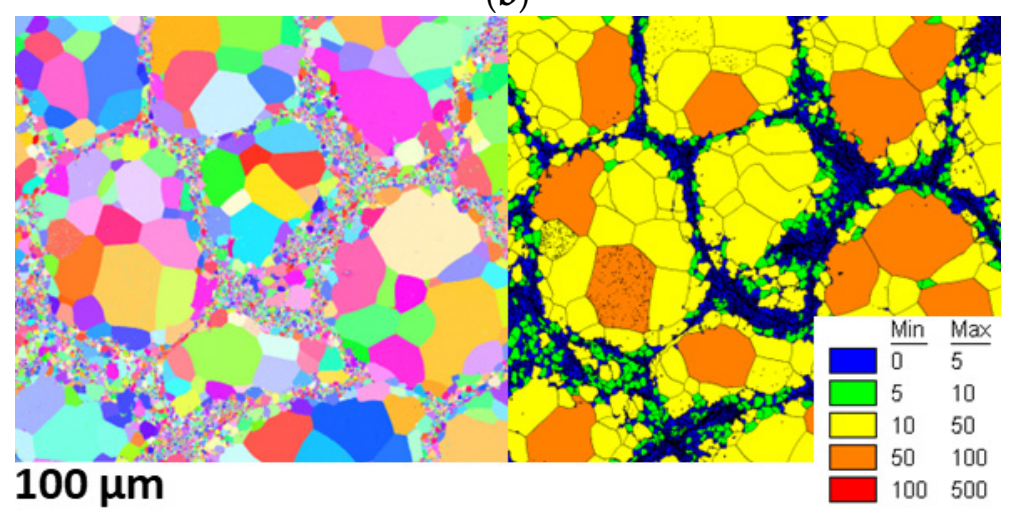

(c)

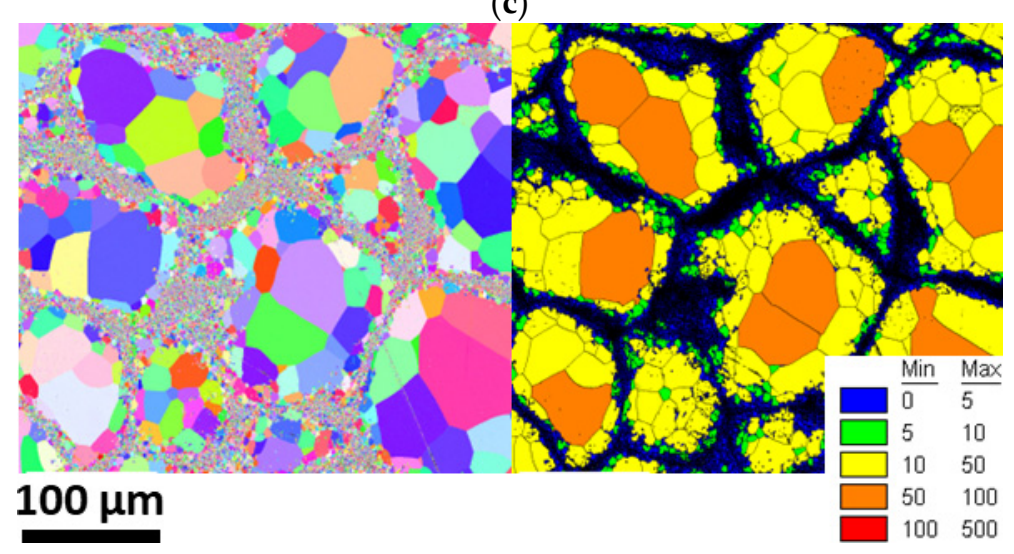

(d)

Figure 6. Cont. 


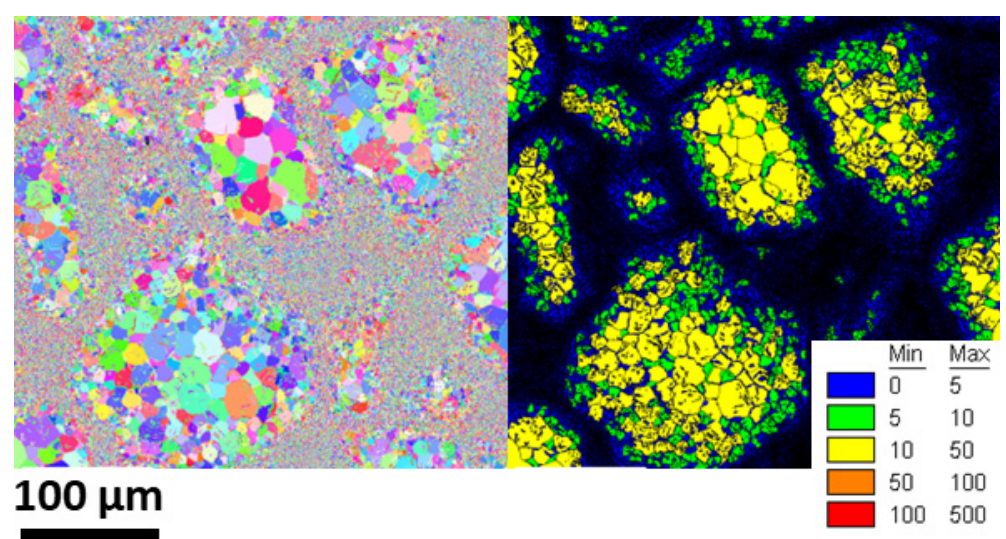

(e)

Figure 6. IPF and grain size maps of as-sintered samples (a) IP (no BM), (b) BM 12 h, (c) BM 25 h, (d) BM $50 \mathrm{~h}$, and (e) BM $100 \mathrm{~h}$. Black lines are drawn as a representation of grain boundaries on grain size maps. Small grains areas appear thus in black, especially in the shell of $(\mathbf{d}, \mathbf{e})$.

Table 1. Microstructural features. A cross $X$ is marked when the sample is not concerned by the microstructural feature.

\begin{tabular}{cccccc}
\hline $\begin{array}{c}\text { Name of the } \\
\text { Sample }\end{array}$ & $\begin{array}{c}\text { Surface } \\
\text { Fraction of the } \\
\text { Shell (\%) }\end{array}$ & $\begin{array}{c}\alpha \text { Phase } \\
\text { Fraction (\%) }\end{array}$ & $\begin{array}{c}\text { Average } \beta \\
\text { Grain Size of } \\
\text { the Core }(\mu \mathrm{m})\end{array}$ & $\begin{array}{c}\text { Average } \beta \\
\text { Grain Size of } \\
\text { the Shell }(\boldsymbol{\mu m})\end{array}$ & $\begin{array}{c}\text { Average } \alpha \\
\text { Grain Size of } \\
\text { the Shell }(\mu \mathrm{m})\end{array}$ \\
\hline IP & $X$ & 0 & 73.7 & $X$ & $X$ \\
\hline BM 12 h & 6.6 & 2.0 & 50.2 & 5.2 & 1.0 \\
\hline BM 25 h & 23.7 & 4.4 & 40.2 & 4.1 & 1.1 \\
\hline BM 50 h & 32.1 & 12.7 & 39.7 & 3.4 & 1.1 \\
\hline BM 100 h & 77.2 & 39.2 & 19.1 & 3.8 & 1.2 \\
\hline
\end{tabular}

From the above data, it is obvious that BM time plays a key role on the shell volume fraction by modifying its width. The longer mechanical BM is processed, the wider the shell region is. The evolution of shell and $\alpha$ phase fractions are plotted versus BM time on Figure 7a and indeed, the shell fraction increases from $6.6 \%$ for BM $12 \mathrm{~h}$ to $77.2 \%$ for a BM $100 \mathrm{~h}$. In return, $\alpha$ phase fraction also increases from $2.0 \%$ (for BM $12 \mathrm{~h}$ ) to 39.2\% (for BM $100 \mathrm{~h}$ ) with BM time. This result could be expected as $\alpha$ phase precipitates on grain boundaries in the shell vicinity. Moreover, as it was said earlier, a long BM stage implies a significant oxygen enrichment of the material, which could favor $\alpha$ phase precipitation. Besides, the evolution of the grain size in the core versus BM time is also plotted on Figure $7 \mathrm{~b}$. The average grain size in the core slightly decreases when BM time increases. This decrease is notably obvious for BM $100 \mathrm{~h}$, which has an average grain size in the core of about $20 \mu \mathrm{m}$, close to the average value of the initial grain size in the powder particles. 


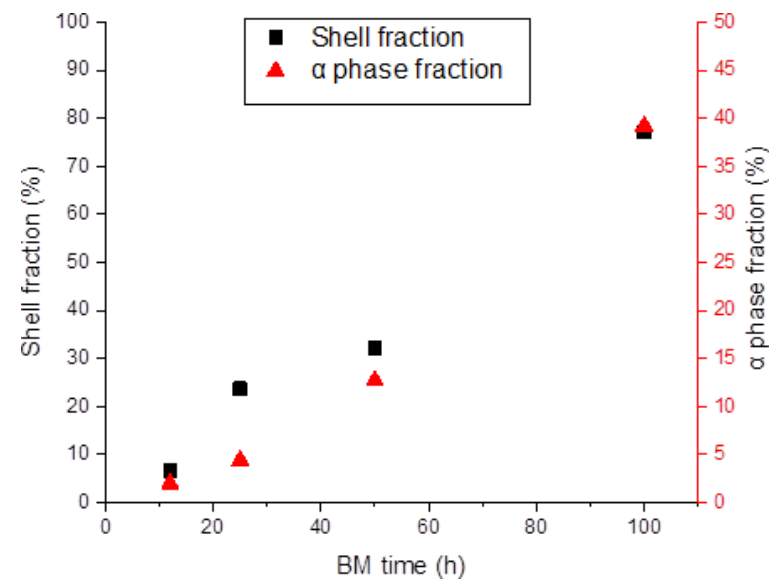

(a)

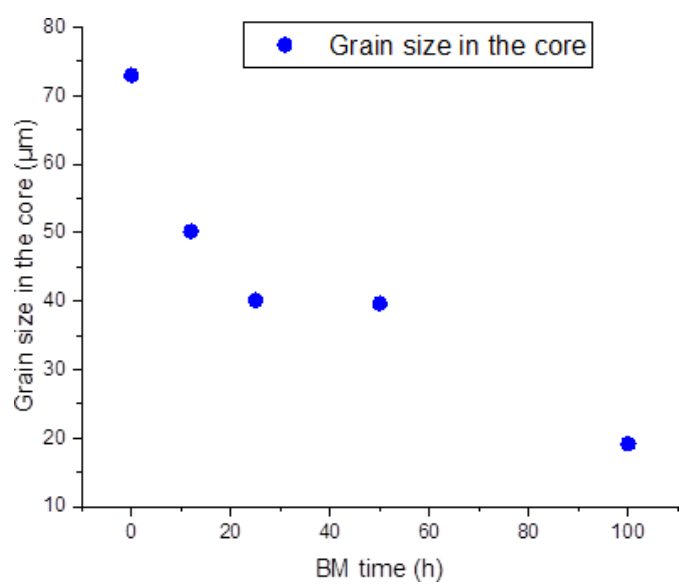

(b)

Figure 7. Evolution of (a) both shell fraction and $\alpha$ phase fraction against BM time and (b) average grain sizes in the core against BM time.

To explain the unusual decrease of grain size in the core with BM time, a particular observation is pointed out for BM $100 \mathrm{~h}$. Indeed, intergranular $\alpha$ phase has precipitated inside the core of this microstructure, which has not been observed for samples processed with a lower BM time. That is probably why $\beta$ grain growth in the core during SPS is limited for BM $100 \mathrm{~h}$ and the average value of grain size in the core is low for this sample.

A comparison of XRD results for all samples is shown on Figure 8. For every BM time, $\beta$ phase peaks are detected on diffractograms. For BM 25 h, BM 50 h, and BM 100 h, additional $\alpha$ peaks are detected and the intensity of these peaks increases with BM time. It confirms the fact that more and more $\alpha$ phase is contained in the samples when BM time is increased. For BM $12 \mathrm{~h}$, the volume fraction of $\alpha$ phase is too low to be detected on XRD, whereas $2.2 \%$ of $\alpha$ phase has been detected thanks to EBSD data. No other unindexed peak is detected on diffractograms.

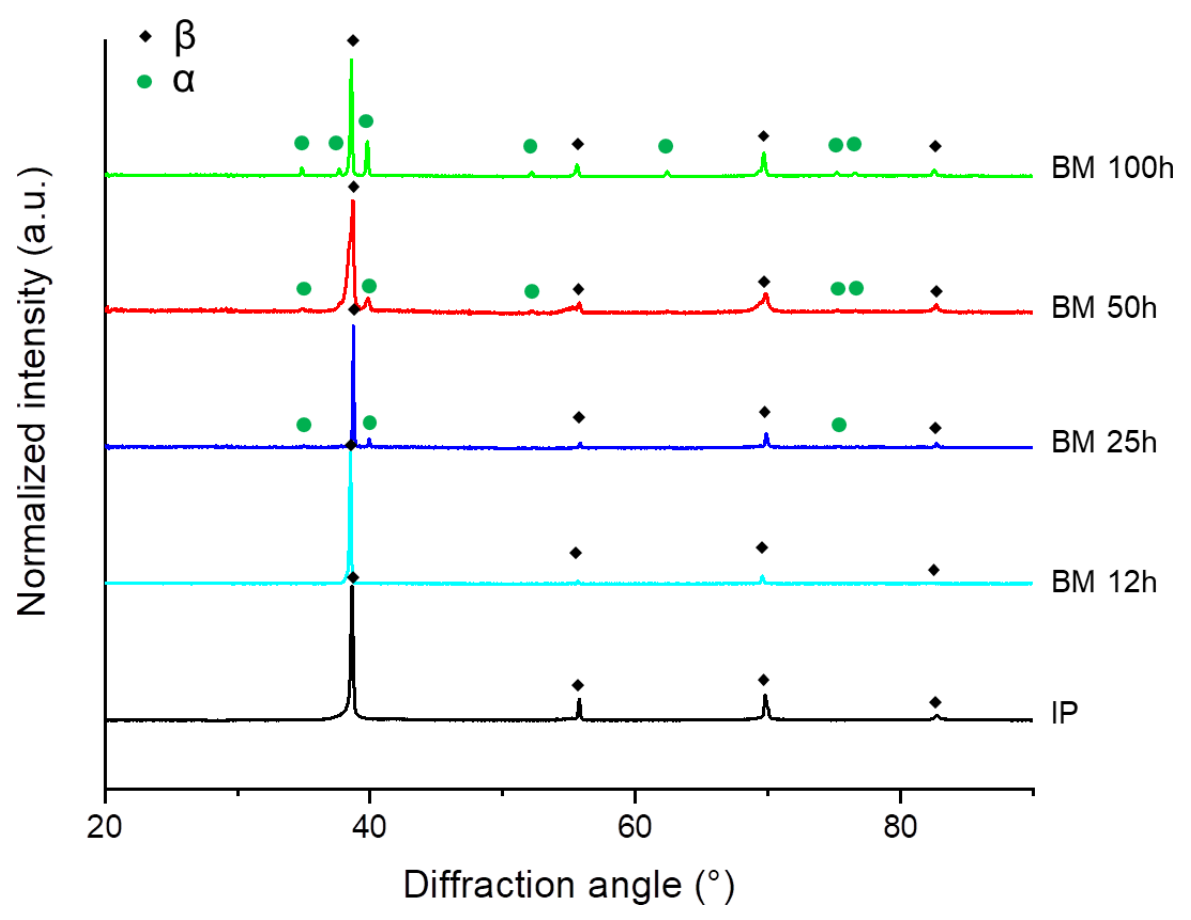

Figure 8. XRD results showing an increase in $\alpha$ phase peak intensities with BM time. 


\subsection{Mechanical Properties of the As-Sintered Ti-2448 Samples}

The samples introduced in the previous part of the study have been mechanically tested using room temperature simple shear tests. Equivalent Von-Mises tensile stress and strain have been computed as: $\sigma=\tau \times \sqrt{3}$ and $\varepsilon=\gamma / \sqrt{3}$, where $\tau$ and $\gamma$ are respectively the shear stress and the shear strain. Figure 9 a shows the equivalent tensile true stress-true strain curves of the simple shear tested samples. The corresponding strain hardening rate evolution against true strain is presented in the insert as Figure 9b.

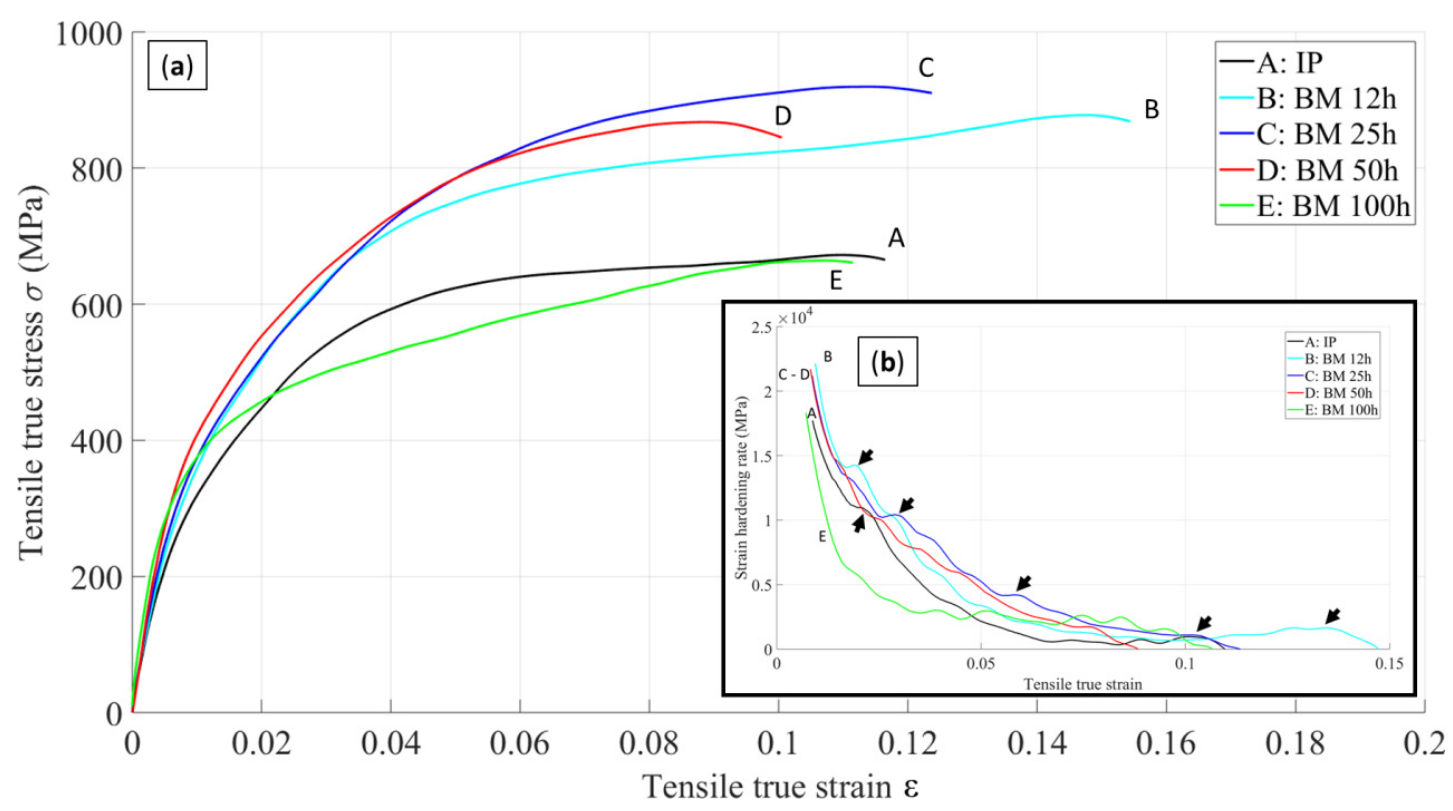

Figure 9. (a) Tensile curves and (b) corresponding strain-hardening rate versus true tensile strain curves. Curves are indexed with letters for clarity: A for the conventional microstructure IP, B for BM $12 \mathrm{~h}, \mathrm{C}$ for BM $25 \mathrm{~h}, \mathrm{D}$ for BM $50 \mathrm{~h}$, and E for BM $100 \mathrm{~h}$.

The mechanical tests have confirmed the high interest of heterogeneous microstructure for a better mechanical performance of materials and processing such heterogeneous materials is promising in order to increase the strength-ductility compromise of Ti-2448. Indeed, when compared with the conventional microstructure IP, both BM 12 h, BM 25 h, and BM 50 h curves reach a higher ultimate tensile stress while keeping comparable values of ductility and the heterogeneity of the microstructure contributes to the global increase of the flow stress. Only BM $100 \mathrm{~h}$ whose microstructure is mainly consisted of sub-micrometric $\alpha$ and $\beta$ grains (about 70\%) reaches a lower ultimate tensile stress value than IP.

At low strain values, i.e. until $2 \%$, heterogeneous microstructures reach higher stress values than the conventional one. However, from this first threshold point, BM $100 \mathrm{~h}$ differentiates from the other heterogeneous samples by starting a stationary regime where the increase of the flow stress is quite linear. Then, BM 12 h, BM 25 h and BM 50 h display a similar mechanical behavior until 4\% strain, which is characterized by several strain hardening rate rebounds-defined as local minima followed by brief increases of the curve. Most of them are marked with black arrows on Figure 9b. The IP sample also benefits from a similar strain hardening rate rebound (also identified with a black arrow on Figure 9b). From this strain value of 4\%, BM 12 h tends to soften, whereas both BM $25 \mathrm{~h}$ and BM $50 \mathrm{~h}$ keep hardening. At the same time, strain hardening rate of BM $100 \mathrm{~h}$ tends to stabilize at about $2.5 \mathrm{GPa}$, between strain values of 4 to $10 \%$; however, stress levels which are reached by this sample are lower than every other sample. Finally, above 6\% strain, BM $25 \mathrm{~h}$ keeps hardening with a last stain hardening rate rebound, whereas BM $12 \mathrm{~h}$ and BM $50 \mathrm{~h}$ do not. Yet, it is interesting to note 
that for BM $12 \mathrm{~h}$, a strain hardening increase starts from a strain of $10 \%$ and keeps going until $14 \%$. It could be the cause of the higher true strain, which is finally reached by BM $12 \mathrm{~h}$.

To explain the differences between shear behaviors, a first series of observations may be made on the elastic domains. Figure 10 is a comparative plot of experimentally and theoretically calculated Young's moduli of the samples. Error bars are calculated thanks to the data of the two mechanical tests which have been performed for each sample and the error on stress and strain measurements. The experimentally calculated modulus corresponds to the slope of the experimental curves whereas the theoretical Young's modulus is calculated using a rule of mixture considering both $\alpha$ and $\beta$ phase fractions and respective Young's moduli. A clear increase of Young's modulus of the samples with BM time is observed, which fits the evolution of the calculated Young's modulus. The evolution of the Young's modulus may be associated with the fact that $\alpha$ phase volume fraction increases when BM time increases. As Young's modulus variations are due to the strength of chemical bonds between atoms, the change in chemistry of the alloy induces a change in the Young's modulus of the alloy. It increases when $\alpha$ phase fraction increases but keeps a rather low value of around $50 \mathrm{GPa}$ for a BM time of $50 \mathrm{~h}$. By interpolating the experimental curve, it may therefore be possible to control the elastic modulus of the as-processed material by controlling BM time. In any case, it remains close to the Young's modulus of human bones (around $30 \mathrm{GPa}$ for cortical human bones) and fulfills one of the requirements for biomedical and orthopedic implants.

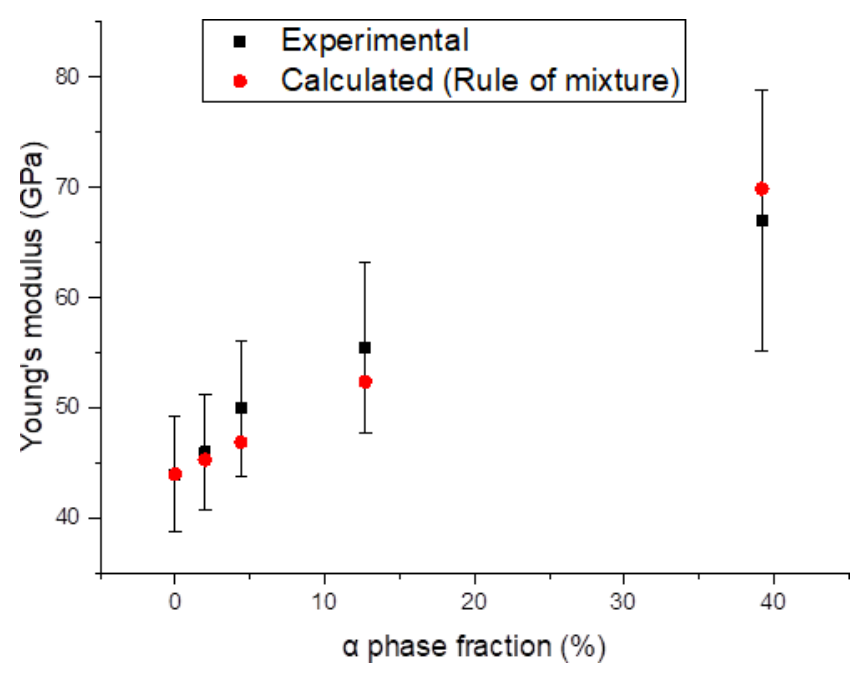

Figure 10. Evolution of Young's modulus (experimentally and theoretically calculated) against the $\alpha$ phase fraction.

Apart from the increase of the Young's modulus with BM time, another global observation could help explaining the differences between the tensile curves of the samples. Indeed, for every sample except BM $100 \mathrm{~h}$, the plots display wide elastic to plastic transition domains. Several hypotheses could be made to explain this unusual behavior. Firstly, it could be linked with the stress-induced martensitic phase transformation which may occur during straining of Ti-2448. For $<110>_{\beta}$ Ti-2448 single crystals, the stress-induced $\beta$ to $\alpha$ " phase transformation takes place at a constant stress and is thus characterized by a plateau on the stress-strain curve $[10,11,42]$. However, for isotropic polycrystals, the stress-induced transformation might occur together with other deformation mechanisms of $\beta$ phase and be characterized by a nonlinear elastic domain and a wide elastic to plastic transition zone $[8,43,44]$. Besides, Ti-2448 is also liable to deform via $\{332\}<113\rangle_{\beta}$ mechanical twinning [10-12,45], and this deformation mechanism could be the cause of the nonlinear elastic domain of the alloy. Finally, it could be linked with the heterogeneity of the as-processed microstructures. There is indeed a significant mechanical contrast between core and shell regions in the harmonic structure. 
In order to get a better understanding of the mechanical behavior of every sample, three different mechanical characteristics have been calculated using experimental data: the conventional yield stress at $0.2 \%$ offset, a chosen $1 \%$ plastic strain offset (due to the difficulty of finding a linear part of the elastic domain from Figure 9) and finally the ultimate tensile stress (UTS). If the stress-induced phase transformation actually takes place during straining, the $0.2 \%$ plastic strain yield stress could also be interpreted as the stress required to induce the martensitic transformation of the $\beta$ phase. They are plotted against BM time on Figure 11. It shows a global increase of the characteristic stresses when increasing BM time until BM $50 \mathrm{~h}$ is reached. BM $12 \mathrm{~h}, \mathrm{BM} 25 \mathrm{~h}$, and BM $50 \mathrm{~h}$ have a close $1 \%$ offset stress. For BM $100 \mathrm{~h}$, both yield stress and ultimate tensile stress are lower than the one of the other samples.

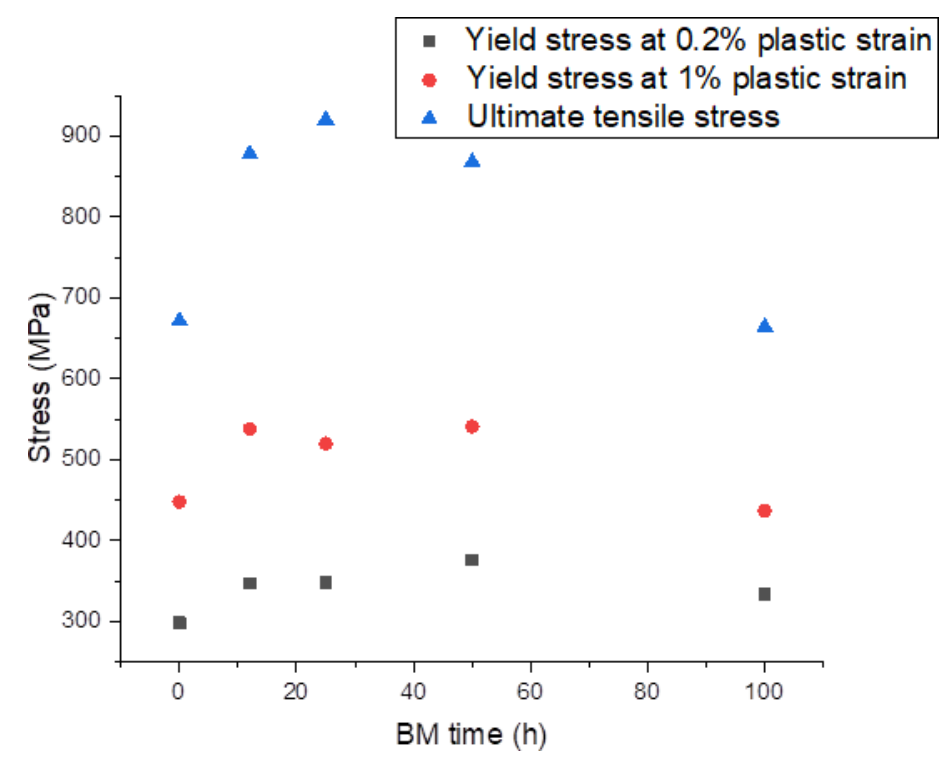

Figure 11. Evolution of yield stresses (at $0.2 \%$ and $1 \%$ plastic strain) and ultimate tensile stress against BM time.

These characteristic values (Figure 11) could be compared with the one in literature, especially those when Ti-2448 is processed by powder metallurgy. Kafkas et al. found UTS values of 650 to $720 \mathrm{MPa}$ for Ti-2448 processed with Metal Injection Molding with coarse grain sizes and carbides precipitates [33]. When Ti-2448 is sintered using elemental powders by Li et al., UTS reaches 750 to $900 \mathrm{MPa}$ according to the microstructure features [32]. Ti-2448 processed with Selective Laser Melting also display similar values of UTS, from 840 to $950 \mathrm{MPa}$ with a heterogeneous microstructure in Yang et al.'s work to $665 \mathrm{MPa}$ in Zhang et al.'s study. This last value may be improved by thermo-mechanical treatments $[35,36]$. In our work, UTS value which is reached by IP sample is comparable to UTS values of as-processed samples in literature, whereas heterogeneous samples have UTS values close to the ones of samples whose microstructure seems to be optimized.

The shear results also suggest a surprising behavior of BM $100 \mathrm{~h}$. Indeed, the mechanical curve of BM $100 \mathrm{~h}$ is completely opposed to what would be expected based on the Hall-Petch relationship. Yet, the Hall-Petch relationship is mainly used for single phase pure metals and alloys whose grains are micron-wide. It is not the case here and consequently it could be an explanation of the differences which are observed between the experimental data and those expected by respect of the Hall-Petch relationship. Besides, the hypothesis which is made here is that $\beta$ to $\alpha^{\prime \prime}$ stress-induced martensitic transformation occurs during shear deformation of IP, BM 12 h, BM 25 h, and BM 50 h. However, both the drastic decrease of grain sizes and the notable increase of the fraction of $\alpha$ precipitates could have inhibited the TRIP and/or TWIP phenomena for BM $100 \mathrm{~h}$. For IP, the stress-induced phase transformation occurs early, but it is delayed when the shell and $\alpha$ fraction are increased in BM $12 \mathrm{~h}$, 
BM $25 \mathrm{~h}$, and BM $50 \mathrm{~h}$. On the contrary, the BM $100 \mathrm{~h}$ material behaves like ultra-fine grain materials (UFG). Indeed, strain hardening rate curve of BM $100 \mathrm{~h}$ is characteristic of the behavior of UFG materials: strain hardening rate is high at the beginning of plastic deformation, but its decrease is very sharp once the second stage of plastic deformation is reached. This behavior is usually associated with a significant lack of ductility [46,47]. Fracture surface of BM $100 \mathrm{~h}$ is by the way characteristic of a brittle material.

The other samples-including IP, BM 12 h, BM 25 h, and BM 50 h-display local minima (followed by either a plateau or an increase) and fluctuations of the strain hardening rate. For IP, the local minimum of the strain hardening rate is followed by a plateau, whereas for heterogeneous ones (BM 12 h, BM 25 h, and BM 50 h), local minima are followed by a short increase of the strain hardening rate. These have been associated in the literature with the activation of a secondary deformation mechanism, which could be twinning or phase transformation [38,48]. However, no twin or martensite traces have been observed for the corresponding deformed post-mortem microstructures, and even for the post-mortem IP conventional microstructure, which is more susceptible to benefit from TRIP and/or TWIP deformation mechanisms. More investigations, including in situ tensile tests and/or cyclic mechanical tests, must be carried out for a better understanding of the global deformation mechanism. Other studies have associated the appearance of fluctuations in strain hardening rate curves with the formation of deformation gradients inside the microstructure [49]. Indeed, in heterogeneous and harmonic structures, the presence of both fine and coarse grains inside the microstructure induces hardness gradients in the microstructure. Coarse grains are easier to deform and start plastic deformation earlier than fine grains regions. Consequently, deformation gradients are formed at the core-shell interfaces which must be accommodated by geometrically necessary dislocations (GNDs). Piling up of GNDs at the core-shell interfaces results in high back stresses acting against the propagation of newly formed dislocations: it is a form of kinematic hardening contributing to the global work hardening of the alloy [50-52]. Fluctuations of the strain hardening rate of BM $12 \mathrm{~h}$, BM $25 \mathrm{~h}$, and BM $50 \mathrm{~h}$ might be the signatures of this kind of deformation mechanism.

The differences in mechanical behavior between samples are also illustrated by the characterization of the post-mortem deformed microstructures which has been carried out using XRD, microscopy, and EBSD. Figure 12 presents post-mortem optical images of the deformed surface of BM $12 \mathrm{~h}, \mathrm{BM} 25 \mathrm{~h}$, BM 50 h, and BM 100 h, whereas Figure 12e presents a SEM secondary electrons close-up view of the deformation bands on IP. Deformation marks are visible on the surface of the samples. For IP and BM $12 \mathrm{~h}$, a very high number of marks is clearly identified. The number of these bands decreases with BM time (and consequently with shell and $\alpha$ precipitates fraction). Indeed, for BM $25 \mathrm{~h}$ and BM $50 \mathrm{~h}$, only a few bands are visible, and no trace is identified for BM $100 \mathrm{~h}$. EBSD investigation has shown that these bands are not twins, even if some similar deformation features have been identified as mechanical twins in recent studies $[11,12]$. Therefore, it may be slip bands. These slip bands are straight and parallel in some grains, whereas in others, they intersect and overlap. It means that several gliding systems are successively activated. Moreover, cross-slip of dislocations also occurs, because of the wavy shape of these deformation traces. Their intersection shows shearing effects (clearly visible on Figure 12e), which could give us information about the timing of the appearance of these bands during deformation. The progressive disappearance of deformation marks with BM time confirms the fact that a change in deformation mechanism of Ti-2448 occurs when it is heterogeneously processed. 


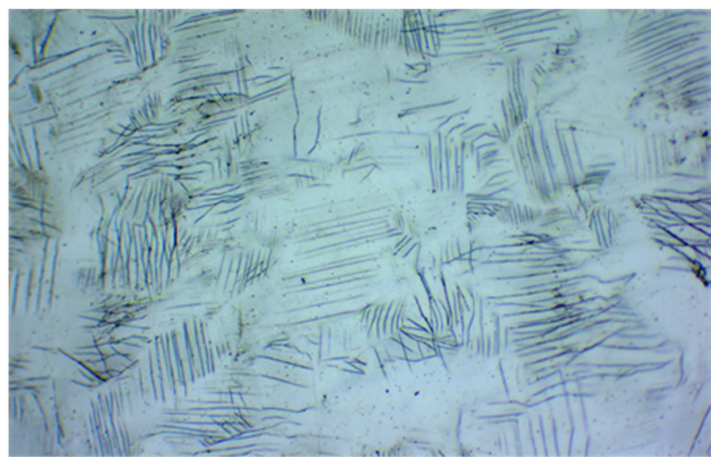

$50 \mu \mathrm{m}$

(a)

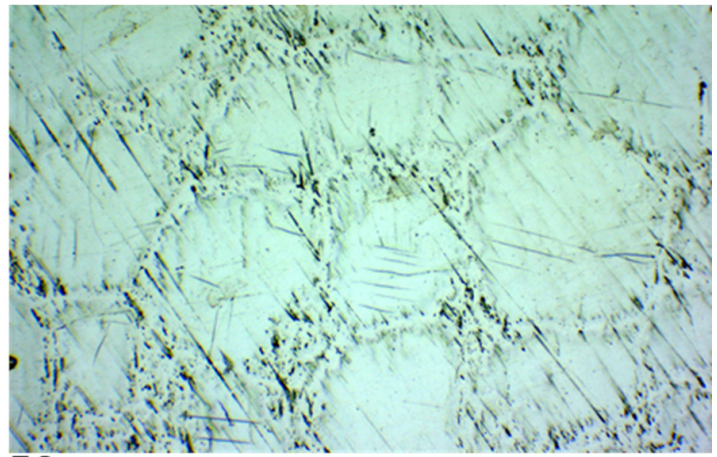

$50 \mu \mathrm{m}$

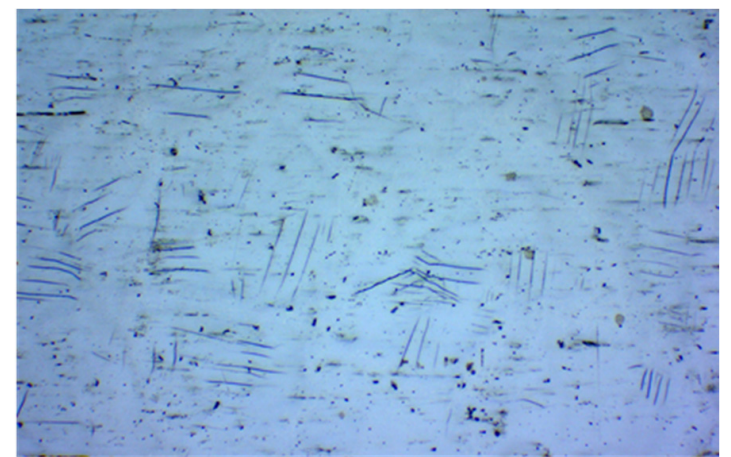

$50 \mu \mathrm{m}$

(b)

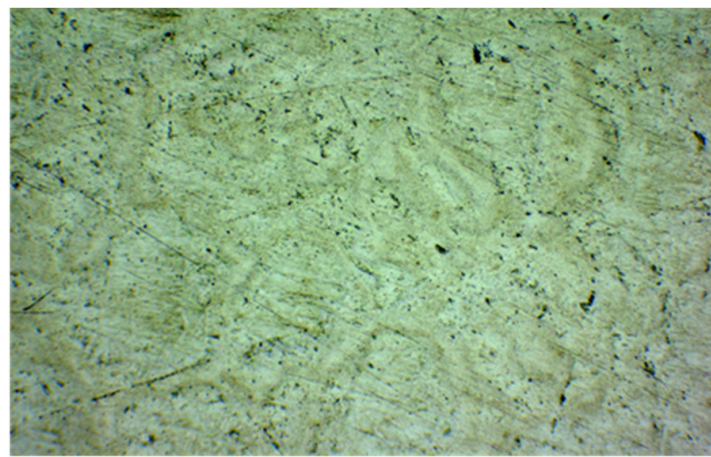

$50 \mu \mathrm{m}$

(d)

(c)

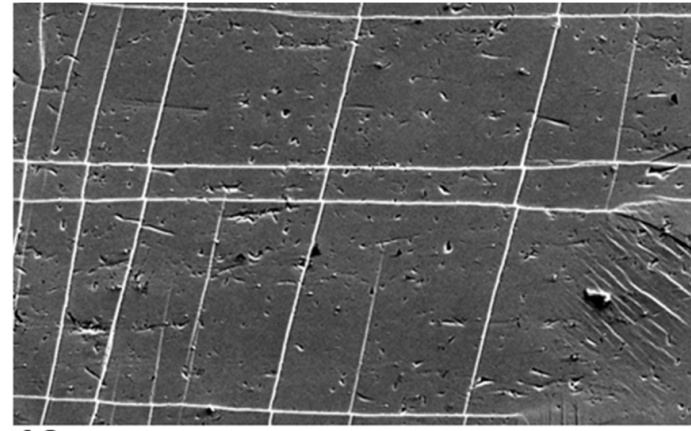

$10 \mu \mathrm{m}$

(e)

Figure 12. Optical images of the surface of the samples after simple shear (a) BM 12 h, (b) BM 25 h, (c) BM $50 \mathrm{~h}$, (d) BM $100 \mathrm{~h}$, and (e) SEM secondary electrons image of deformation bands on the surface of the IP sample.

\section{Conclusions}

This study has highlighted different mechanical responses of Ti-2448 samples according to the powder metallurgy processing route. These differences may reasonably be figured out. Indeed, several microstructural features have been modified by playing with the processing parameters, including grain sizes in both core and shell, chemical concentrations, and $\alpha$ phase precipitation. Most of these features have been shown to play a role in the deformation mechanism of $\beta$-metastable titanium alloys. The chemical composition of the alloy, and most particularly the oxygen content, is indeed of primary importance on the stress-induced $\beta$ to $\alpha^{\prime \prime}$ phase transformation [53]. Grain sizes also influence the appearance of phase transformation and mechanical twinning in the deformation sequence of 
$\beta$-metastable alloys [54,55]. Finally, precipitation of $\alpha$ and/or $\omega$ phases also significantly influences the mechanical behavior of Ti-2448 [43,56].

Author Contributions: Conceptualization, D.T. and G.D.; investigation, B.F., A.H. and E.L.; methodology, B.F., D.T. and Y.H.; resources, Y.H. and F.P.; supervision, D.T., F.P. and G.D.; writing-original draft, B.F.; writing-review \& editing, F.P. and G.D. All authors have read and agreed to the published version of the manuscript.

Funding: This research received no external funding.

Conflicts of Interest: The authors declare no conflict of interest.

\section{References}

1. Banerjee, D.; Williams, J.C. Perspectives on Titanium Science and Technology. Acta Mater. 2013, 61, 844-879. [CrossRef]

2. Steinemann, S.G. Metal implants and surface reactions. Injury 1996, 27, S/C16-S/C22. [CrossRef]

3. Hao, Y.L.; Li, S.J.; Sun, S.Y.; Zheng, C.Y.; Yang, R. Elastic deformation behaviour of Ti-24Nb-4Zr-7.9Sn for biomedical applications. Acta Biomater. 2007, 3, 277-286. [CrossRef] [PubMed]

4. Zhang, Y.W.; Li, S.J.; Obbard, E.G.; Wang, H.; Wang, S.C.; Hao, Y.L.; Yang, R. Elastic properties of $\mathrm{Ti}-24 \mathrm{Nb}-4 \mathrm{Zr}-8 \mathrm{Sn}$ single crystals with bcc crystal structure. Acta Mater. 2011, 59, 3081-3090. [CrossRef]

5. Hao, Y.L.; Li, S.J.; Sun, S.Y.; Yang, R. Effect of Zr and Sn on Young's modulus and superelasticity of Ti-Nb-based alloys. Mater. Sci. Eng. A 2006, 441, 112-118. [CrossRef]

6. Arifin, A.; Sulong, A.B.; Muhamad, N.; Syarif, J.; Ramli, M.I. Material processing of hydroxyapatite and titanium alloy (HA/Ti) composite as implant materials using powder metallurgy: A review. Mater. Des. 2014, 55, 165-175. [CrossRef]

7. Qu, Y.; Zheng, S.; Dong, R.; Kang, M.; Zhou, H.; Zhao, D.; Zhao, J. Ti-24Nb-4Zr-8Sn Alloy Pedicle Screw Improves Internal Vertebral Fixation by Reducing Stress-Shielding Effects in a Porcine Model. Available online: https://www.hindawi.com/journals/bmri/2018/8639648/ (accessed on 23 March 2020).

8. Yang, Y.; Castany, P.; Cornen, M.; Prima, F.; Li, S.J.; Hao, Y.L.; Gloriant, T. Characterization of the martensitic transformation in the superelastic Ti-24Nb-4Zr-8Sn alloy by in situ synchrotron $\mathrm{X}$-ray diffraction and dynamic mechanical analysis. Acta Mater. 2015, 88, 25-33. [CrossRef]

9. Yang, Y.; Castany, P.; Cornen, M.; Thibon, I.; Prima, F.; Gloriant, T. Texture investigation of the superelastic Ti-24Nb-4Zr-8Sn alloy. J. Alloys Compd. 2014, 591, 85-90. [CrossRef]

10. Yao, T.; Du, K.; Wang, H.; Huang, Z.; Li, C.; Li, L.; Hao, Y.; Yang, R.; Ye, H. In situ scanning and transmission electron microscopy investigation on plastic deformation in a metastable $\beta$ titanium alloy. Acta Mater. 2017, 133, 21-29. [CrossRef]

11. Yang, Y.; Castany, P.; Bertrand, E.; Cornen, M.; Lin, J.X.; Gloriant, T. Stress release-induced interfacial twin boundary $\omega$ phase formation in a $\beta$ type Ti-based single crystal displaying stress-induced $\alpha^{\prime \prime}$ martensitic transformation. Acta Mater. 2018, 149, 97-107. [CrossRef]

12. Liang, Q.; Kloenne, Z.; Zheng, Y.; Wang, D.; Antonov, S.; Gao, Y.; Hao, Y.; Yang, R.; Wang, Y.; Fraser, H.L. The role of nano-scaled structural non-uniformities on deformation twinning and stress-induced transformation in a cold rolled multifunctional $\beta$-titanium alloy. Scr. Mater. 2020, 177, 181-185. [CrossRef]

13. Li, S.J.; Jia, M.T.; Prima, F.; Hao, Y.L.; Yang, R. Improvements in nonlinear elasticity and strength by grain refinement in a titanium alloy with high oxygen content. Scr. Mater. 2011, 64, 1015-1018. [CrossRef]

14. Zhang, S.Q.; Li, S.J.; Jia, M.T.; Prima, F.; Chen, L.J.; Hao, Y.L.; Yang, R. Low-cycle fatigue properties of a titanium alloy exhibiting nonlinear elastic deformation behavior. Acta Mater. 2011, 59, 4690-4699. [CrossRef]

15. Prima, F.; Vermaut, P.; Texier, G.; Ansel, D.; Gloriant, T. Evidence of $\alpha$-nanophase heterogeneous nucleation from $\omega$ particles in a $\beta$-metastable Ti-based alloy by high-resolution electron microscopy. Scr. Mater. 2006, 54, 645-648. [CrossRef]

16. Zheng, Y.; Williams, R.E.A.; Sosa, J.M.; Wang, Y.; Banerjee, R.; Fraser, H.L. The role of the $\omega$ phase on the non-classical precipitation of the $\alpha$ phase in metastable $\beta$-titanium alloys. Scr. Mater. 2016, 111, 81-84. [CrossRef]

17. Li, C.; Chen, J.; Li, W.; Ren, Y.J.; He, J.J.; Song, Z.X. Effect of heat treatment variations on the microstructure evolution and mechanical properties in a $\beta$ metastable Ti alloy. J. Alloys Compd. 2016, 684, 466-473. [CrossRef] 
18. Abdel-Hady, M.; Hinoshita, K.; Morinaga, M. General approach to phase stability and elastic properties of $\beta$-type Ti-alloys using electronic parameters. Scr. Mater. 2006, 55, 477-480. [CrossRef]

19. Lai, M.J.; Tasan, C.C.; Raabe, D. On the mechanism of $\{332\}$ twinning in metastable $\beta$ titanium alloys. Acta Mater. 2016, 111, 173-186. [CrossRef]

20. Marteleur, M.; Sun, F.; Gloriant, T.; Vermaut, P.; Jacques, P.J.; Prima, F. On the design of new $\beta$-metastable titanium alloys with improved work hardening rate thanks to simultaneous TRIP and TWIP effects. Scr. Mater. 2012, 66, 749-752. [CrossRef]

21. Li, Z.; Zheng, B.; Wang, Y.; Topping, T.; Zhou, Y.; Valiev, R.Z.; Shan, A.; Lavernia, E.J. Ultrafine-grained Ti-Nb-Ta-Zr alloy produced by ECAP at room temperature. J. Mater. Sci. 2014, 49, 6656-6666. [CrossRef]

22. Shin, S.; Zhu, C.; Zhang, C.; Vecchio, K.S. Extraordinary strength-ductility synergy in a heterogeneous-structured $\beta$-Ti alloy through microstructural optimization. Mater. Res. Lett. 2019, 7, 467-473. [CrossRef]

23. Lu, K. Making strong nanomaterials ductile with gradients. Science 2014, 345, 1455-1456. [CrossRef] [PubMed]

24. Yang, M.; Yan, D.; Yuan, F.; Jiang, P.; Ma, E.; Wu, X. Dynamically reinforced heterogeneous grain structure prolongs ductility in a medium-entropy alloy with gigapascal yield strength. Proc. Natl. Acad. Sci. USA 2018, 115, 7224-7229. [CrossRef]

25. Vajpai, S.K.; Ota, M.; Zhang, Z.; Ameyama, K. Three-dimensionally gradient harmonic structure design: An integrated approach for high performance structural materials. Mater. Res. Lett. 2016, 4, 191-197. [CrossRef]

26. Vajpai, S.K.; Sawangrat, C.; Yamaguchi, O.; Ciuca, O.P.; Ameyama, K. Effect of bimodal harmonic structure design on the deformation behaviour and mechanical properties of Co-Cr-Mo alloy. Mater. Sci. Eng. C 2016, 58, 1008-1015. [CrossRef] [PubMed]

27. Zhang, Z.; Vajpai, S.K.; Orlov, D.; Ameyama, K. Improvement of mechanical properties in SUS304L steel through the control of bimodal microstructure characteristics. Mater. Sci. Eng. A 2014, 598, 106-113. [CrossRef]

28. Kikuchi, S.; Hayami, Y.; Ishiguri, T.; Guennec, B.; Ueno, A.; Ota, M.; Ameyama, K. Effect of bimodal grain size distribution on fatigue properties of Ti-6Al-4V alloy with harmonic structure under four-point bending. Mater. Sci. Eng. A 2017, 687, 269-275. [CrossRef]

29. Weston, N.S.; Derguti, F.; Tudball, A.; Jackson, M. Spark plasma sintering of commercial and development titanium alloy powders. J. Mater. Sci. 2015, 50, 4860-4878. [CrossRef]

30. Weston, N.S.; Jackson, M. FAST-forge of Titanium Alloy Swarf: A Solid-State Closed-Loop Recycling Approach for Aerospace Machining Waste. Metals 2020, 10, 296. [CrossRef]

31. Bodunrin, M.O.; Chown, L.H.; Omotoyinbo, J.A. Development of low-cost titanium alloys: A chronicle of challenges and opportunities. Mater. Today Proc. 2020, S2214785320317685. [CrossRef]

32. Li, X.; Ye, S.; Yuan, X.; Yu, P. Fabrication of biomedical Ti-24Nb-4Zr-8Sn alloy with high strength and low elastic modulus by powder metallurgy. J. Alloys Compd. 2019, 772, 968-977. [CrossRef]

33. Kafkas, F.; Ebel, T. Metallurgical and mechanical properties of Ti-24Nb-4Zr-8Sn alloy fabricated by metal injection molding. J. Alloys Compd. 2014, 617, 359-366. [CrossRef]

34. Liu, Y.; Li, S.; Hou, W.; Wang, S.; Hao, Y.; Yang, R.; Sercombe, T.B.; Zhang, L.-C. Electron Beam Melted Beta-type Ti-24Nb-4Zr-8Sn Porous Structures with High Strength-to-Modulus Ratio. J. Mater. Sci. Technol. 2016, 32, 505-508. [CrossRef]

35. Yang, C.L.; Zhang, Z.J.; Li, S.J.; Liu, Y.J.; Sercombe, T.B.; Hou, W.T.; Zhang, P.; Zhu, Y.K.; Hao, Y.L.; Zhang, Z.F.; et al. Simultaneous improvement in strength and plasticity of Ti-24Nb-4Zr-8Sn manufactured by selective laser melting. Mater. Des. 2018, 157, 52-59. [CrossRef]

36. Zhang, L.C.; Klemm, D.; Eckert, J.; Hao, Y.L.; Sercombe, T.B. Manufacture by selective laser melting and mechanical behavior of a biomedical Ti-24Nb-4Zr-8Sn alloy. Scr. Mater. 2011, 65, 21-24. [CrossRef]

37. Zheng, R.; Zhang, Z.; Nakatani, M.; Ota, M.; Chen, X.; Ma, C.; Ameyama, K. Enhanced ductility in harmonic structure designed SUS316L produced by high energy ball milling and hot isostatic sintering. Mater. Sci. Eng. A 2016, 674, 212-220. [CrossRef]

38. Dirras, G.; Ueda, D.; Hocini, A.; Tingaud, D.; Ameyama, K. Cyclic shear behavior of conventional and harmonic structure-designed Ti-25Nb-25Zr $\beta$-titanium alloy: Back-stress hardening and twinning inhibition. Scr. Mater. 2017, 138, 44-47. [CrossRef] 
39. Mompiou, F.; Tingaud, D.; Chang, Y.; Gault, B.; Dirras, G. Conventional vs harmonic-structured $\beta$-Ti-25Nb-25Zr alloys: A comparative study of deformation mechanisms. Acta Mater. 2018, 161, 420-430. [CrossRef]

40. Combres, Y. Propriétés Du Titane Et De Ses Alliages; Techniques de l'ingénieur: Paris, France, 2010.

41. Chou, K.; Marquis, E.A. Oxygen effects on $\omega$ and $\alpha$ phase transformations in a metastable $\beta$ Ti-Nb alloy. Acta Mater. 2019, 181, 367-376. [CrossRef]

42. Yao, T.; Du, K.; Wang, H.; Qi, L.; He, S.; Hao, Y.; Yang, R.; Ye, H. Reversible twin boundary migration between $\alpha^{\prime \prime}$ martensites in a Ti-Nb-Zr-Sn alloy. Mater. Sci. Eng. A 2017, 688, 169-173. [CrossRef]

43. Sun, F.; Hao, Y.L.; Zhang, J.Y.; Prima, F. Contribution of nano-sized lamellar microstructure on recoverable strain of Ti-24Nb-4Zr-7.9Sn titanium alloy. Mater. Sci. Eng. A 2011, 528, 7811-7815. [CrossRef]

44. Hao, Y.L.; Zhang, Z.B.; Li, S.J.; Yang, R. Microstructure and mechanical behavior of a Ti-24Nb-4Zr-8Sn alloy processed by warm swaging and warm rolling. Acta Mater. 2012, 60, 2169-2177. [CrossRef]

45. Yang, Y.; Castany, P.; Hao, Y.L.; Gloriant, T. Plastic deformation via hierarchical nano-sized martensitic twinning in the metastable $\beta$ Ti-24Nb-4Zr-8Sn alloy. Acta Mater. 2020, 194, 27-39. [CrossRef]

46. Shumilin, S.E.; Janecek, M.; Isaev, N.V.; Homola, P.; Kral, R. Low Temperature Plasticity of an Ultrafine-Grained Al-3Mg Alloy Prepared by Accumulative Roll Bonding. Adv. Eng. Mater. 2012, 14, 35-38. [CrossRef]

47. Krasilnikov, N.; Lojkowski, W.; Pakiela, Z.; Valiev, R. Tensile strength and ductility of ultra-fine-grained nickel processed by severe plastic deformation. Mater. Sci. Eng. A 2005, 397, 330-337. [CrossRef]

48. Ueda, D.; Dirras, G.; Hocini, A.; Tingaud, D.; Ameyama, K.; Langlois, P.; Vrel, D.; Trzaska, Z. Data on processing of Ti-25Nb-25Zr $\beta$-titanium alloys via powder metallurgy route: Methodology, microstructure and mechanical properties. Data Brief 2018, 17, 703-708. [CrossRef]

49. Jiang, F.; Zhao, C.; Liang, D.; Zhu, W.; Zhang, Y.; Pan, S.; Ren, F. In-situ formed heterogeneous grain structure in spark-plasma-sintered CoCrFeMnNi high-entropy alloy overcomes the strength-ductility trade-off. Mater. Sci. Eng. A 2020, 771, 138625. [CrossRef]

50. Wu, X.; Zhu, Y. Heterogeneous materials: A new class of materials with unprecedented mechanical properties. Mater. Res. Lett. 2017, 5, 527-532. [CrossRef]

51. Wang, Y.F.; Wang, M.S.; Fang, X.T.; Guo, F.J.; Liu, H.Q.; Scattergood, R.O.; Huang, C.X.; Zhu, Y.T. Extra strengthening in a coarse/ultrafine grained laminate: Role of gradient interfaces. Int. J. Plast. 2019, 123, $196-207$. [CrossRef]

52. Yang, M.; Pan, Y.; Yuan, F.; Zhu, Y.; Wu, X. Back stress strengthening and strain hardening in gradient structure. Mater. Res. Lett. 2016, 4, 145-151. [CrossRef]

53. Obbard, E.G.; Hao, Y.L.; Talling, R.J.; Li, S.J.; Zhang, Y.W.; Dye, D.; Yang, R. The effect of oxygen on $\alpha^{\prime \prime}$ martensite and superelasticity in Ti-24Nb-4Zr-8Sn. Acta Mater. 2011, 59, 112-125. [CrossRef]

54. Bhattacharjee, A.; Bhargava, S.; Varma, V.K.; Kamat, S.V.; Gogia, A.K. Effect of $\beta$ grain size on stress induced martensitic transformation in $\beta$ solution treated Ti-10V-2Fe-3Al alloy. Scr. Mater. 2005, 53, 195-200. [CrossRef]

55. Danard, Y.; Sun, F.; Gloriant, T.; Freiherr Von Thüngen, I.; Piellard, M.; Prima, F. The Influence of Twinning on the Strain-Hardenability in TRIP/TWIP Titanium Alloys: Role of Solute-Solution Strengthening. Front. Mater. 2020, 7. [CrossRef]

56. Coakley, J.; Rahman, K.M.; Vorontsov, V.A.; Ohnuma, M.; Dye, D. Effect of precipitation on mechanical properties in the $\beta$-Ti alloy Ti-24Nb-4Zr-8Sn. Mater. Sci. Eng. A 2016, 655, 399-407. [CrossRef]

Publisher's Note: MDPI stays neutral with regard to jurisdictional claims in published maps and institutional affiliations.

(C) 2020 by the authors. Licensee MDPI, Basel, Switzerland. This article is an open access article distributed under the terms and conditions of the Creative Commons Attribution (CC BY) license (http://creativecommons.org/licenses/by/4.0/). 